\title{
Hybrid laser-assisted forming process for ultralight three- dimensional glass elements
}

\author{
Robin Hassel ${ }^{1, *}$, Andrea Barz ${ }^{1}$, Jens Bliedtner ${ }^{1}$, Jörg Steuer ${ }^{2},{\text { Hans } \text { Pitcha }^{2} \text {, and Matthias Eberlein }}^{2}$ \\ ${ }^{1}$ Ernst-Abbe University of Applied Sciences Jena, Carl-Zeiss-Promenade 2, 07745 Jena, Germany \\ ${ }^{2}$ GLAMACO GmbH, Prasseweg 1, 01640 Coswig, Germany
}

\begin{abstract}
As part of a research project, a new hybrid forming process for ultrathin three-dimensional glass elements was developed. In a continuous process chain, the three-part procedure enables large-area gravityassisted bending of thin glass, partial deep-drawing of individual small structures using $\mathrm{CO}_{2}$ laser radiation and cutting of flexible inner and outer contours. Using an experimental setup with a laser scanning system, novel component designs can be generated in a highly flexible and reproducible manner. This can open up new application fields or expand existing ones, for example in the area of cover glasses for display technology.
\end{abstract}

\section{Introduction}

Current manufacturing processes allow large-area forming, especially for thin glasses (thickness $\leq 2.0 \mathrm{~mm}$ ), only to a limited extent. Furthermore, the creation of filigree structures with high aspect ratios is hardly possible to reproduce for preformed glass. Due to the constantly developing technology, glass manufacturers and consumers are increasingly demanding flexibly bent thin glasses with large surface dimensions and simultaneously filigree elements. The weight of the glass should be as low as possible, while the strength and the achievable accuracies should be high. In order to realise such glass elements according to the described requirements with high optical qualities in low processing times, an innovative hybrid forming process was developed.

\section{Glass forming process}

\subsection{Materials}

The hybrid procedure can be used to process borosilicate and alumosilicate glasses with maximum dimensions of $250 \times 250 \mathrm{~mm}^{2}$ and thicknesses between 0.5 and $2.0 \mathrm{~mm}$. To be able to bend or deep-draw the glasses, the viscosity must be reduced. This requires temperatures close to or above the material specific softening point $\left(\mathrm{T}_{\text {Softening }}\right)$. To simplify the handling of viscosity-temperature values, fixed points have been defined representing characteristic viscosities. [1]

The fixed points of the materials used are shown in Table 1.
Table 1. Viscosity fixed points of the glass materials used.

\begin{tabular}{|c|c|c|}
\hline & $\begin{array}{c}\text { BORO- } \\
\text { FLOAT }^{\circledR} 33\end{array}$ & $\begin{array}{c}\text { Xensation }^{\circledR} \\
\text { Cover }\end{array}$ \\
\hline $\begin{array}{c}\text { Annealing Point } \\
\left(\eta=10^{13.0} \mathrm{dPas}\right)\end{array}$ & $560^{\circ} \mathrm{C}$ & $635^{\circ} \mathrm{C}$ \\
\hline $\begin{array}{c}\text { Softening Point } \\
\left(\eta=10^{7.6} \mathrm{dPas}\right)\end{array}$ & $820^{\circ} \mathrm{C}$ & $880^{\circ} \mathrm{C}$ \\
\hline $\begin{array}{c}\text { Working Point } \\
\left(\eta=10^{4.0} \mathrm{dPas}\right)\end{array}$ & $1270^{\circ} \mathrm{C}$ & $1265^{\circ} \mathrm{C}$ \\
\hline
\end{tabular}

With the help of the fixed points and the VOGELFULCHER-TAMMANN equation, the relationship between temperature and viscosity above the transformation range can be approximately calculated. [2]

$$
\lg \eta=A+\frac{B}{T-T_{0}}
$$

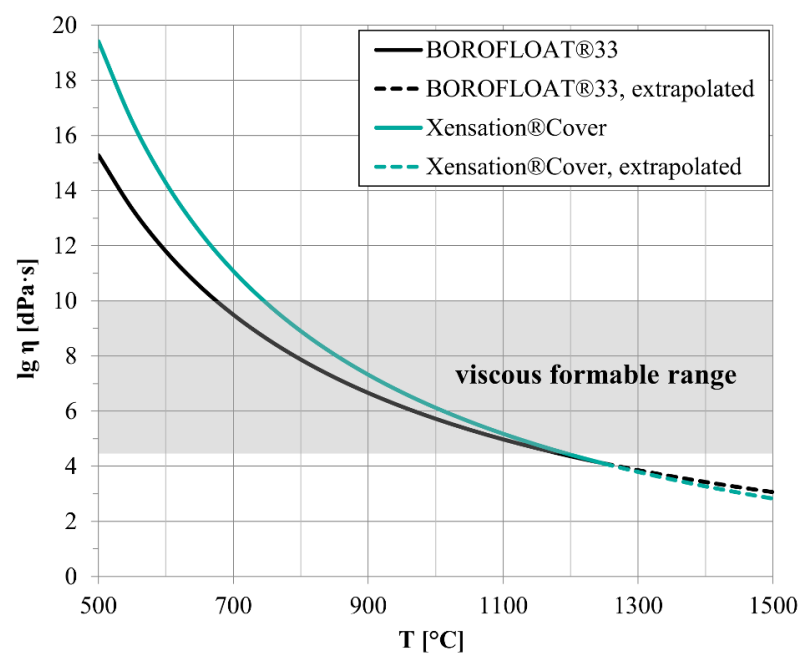

Fig. 1. Viscosity-temperature curves of the materials used.

\footnotetext{
* Corresponding author: robin.hassel@eah-jena.de
} 
The viscosity-temperature curves shown in Fig. 1 provide information on the necessary forming temperatures.

\subsection{Experimental setup and procedure}

As a result of high coefficients of thermal expansion, the glasses used have a relatively low thermal shock resistance. Therefore, laser processing at room temperature is almost impossible. To avoid glass breakage, the glasses are preheated in a heating chamber (GLAMACO GmbH) before laser processing. The experimental setup, which is divided into two parts on a laboratory scale, is illustrated schematically in Fig. 2.

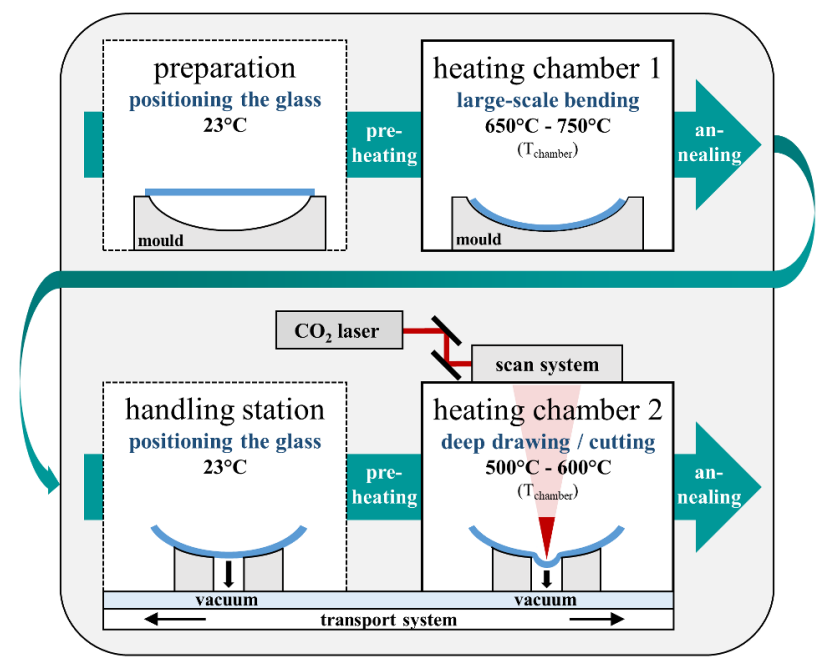

Fig. 2. Principle of the hybrid forming process of thin glass.

To bend larger geometries, the entire glass component is heated in a thermal chamber to a suitable temperature below the softening point, which allows forming but precludes flowing of the glass to prevent undesirable deformation and glass thickness changes. The mould used must be dimensionally stable and heat-resistant. It should also have a surface roughness that prevents sticking behaviour between glass and mould and at the same time ensures a high surface quality of the formed glass.

For the deep-drawing of filigree elements, defined areas of the glass are heated by $\mathrm{CO}_{2}$ laser radiation $(\lambda=10,6 \mu \mathrm{m})$ and thermoformed with vacuum support and without an underlying forming tool. By using a laser scanning system, freely designable contours of different depths can be generated with high precision. Due to the locally limited heat input, these structures can also be realised in already preformed glass without undesirably deforming it. This results in considerable energy and time savings since not the entire glass component has to be heated to forming temperature.

In the final step of the hybrid process, the preheated glass is cut by using $\mathrm{CO}_{2}$ laser radiation. The same beam source can be used for cutting as for deep-drawing. A focusing optic (flat field lens with a focus length of 600 $\mathrm{mm}$ ) is used to achieve the high intensities required for the cutting process. A mechanical lifting device inside the chamber ensures the sample movement along the z-axis so that the glass can be positioned in the focal plane. The laser beam tool allows not only the individual cutting of outer contours, but also the generation of flexible inner contours with good (cutting) edge qualities. [3]

During the laser-based processes, the influence of the following parameters is investigated:

- preheating temperature $\left[{ }^{\circ} \mathrm{C}\right]$

- values of laser power [W]

- values of scanning speed $\left[\mathrm{m} \cdot \mathrm{s}^{-1}\right]$

- laser scanning strategies

- number of scans (exposure time)

Finally, the influence on the following output parameters is examined:

- process temperature $\left[{ }^{\circ} \mathrm{C}\right]$

- contour width and length

- contour depth

- surface and edge quality

- state of thermal stress

\section{Results}

With the described experimental setup, the sub-processes of the hybrid forming process could be successfully and reproducibly implemented on thin borosilicate and alumosilicate glasses using previously determined process parameters (such as temperature and laser power).

In numerous investigations the technological process windows for the sub-processes could be determined. For gravity-assisted bending, temperatures below the material-specific softening point are sufficient, whereas temperatures above this point are required for laserassisted deep-drawing. The use of laser radiation in combination with the scanning system offers many advantages. In particular, the flexibility and individuality with regard to three-dimensional structures of different depths that can be generated is increased enormously. In addition, the processing times are very short due to the high scanning speeds and the fast energy input into the glass component. The hybrid process approach and the associated interaction of multiple sub-processes and energy sources can increase the performance of the glass forming procedure compared to conventional processes.

Fig. 3 shows a three-dimensionally formed borosilicate glass component with a thickness of $0.7 \mathrm{~mm}$ produced by the hybrid forming process.

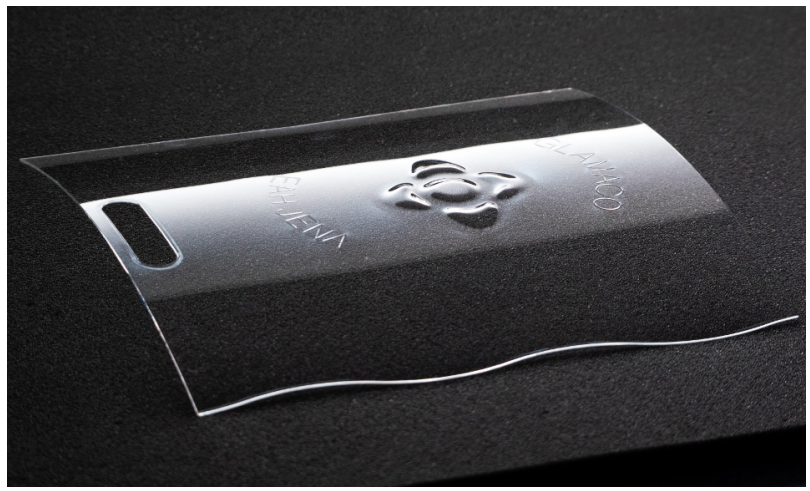

Fig. 3. Generated borosilicate glass component ( $0.7 \mathrm{~mm}$ thick). 
Deep-drawing without a mould is associated with the reduction of processing time, energy and costs. Moreover, there is no (negative) mechanical impact on the glass surface. By varying the laser beam diameter, even structures with small bending radii and high aspect ratios can be generated with high accuracies. In this context, it is possible to achieve contours with a flat-edged design on the one hand and sharply defined contours on the other. The locally limited laser processing and the associated high temperature gradients result in undesirable thermal stresses in the glass. For this reason, the laser treatment is followed by an annealing process in order to reduce relieve residual internal stresses to a non-critical level. Besides annealing and chemical strengthening of glass, no time-consuming post-processing steps are necessary. [3]

Further investigations demonstrate that the process described allows not only two-dimensional bending but also three-dimensional large-area bending of thin glass. As exemplified in Fig. 4, special forming tools (a) can be used to bend thin glasses with a thickness of $1.0 \mathrm{~mm}$ as parabolic mirrors with a diameter of $70 \mathrm{~mm}$ (b). [4]
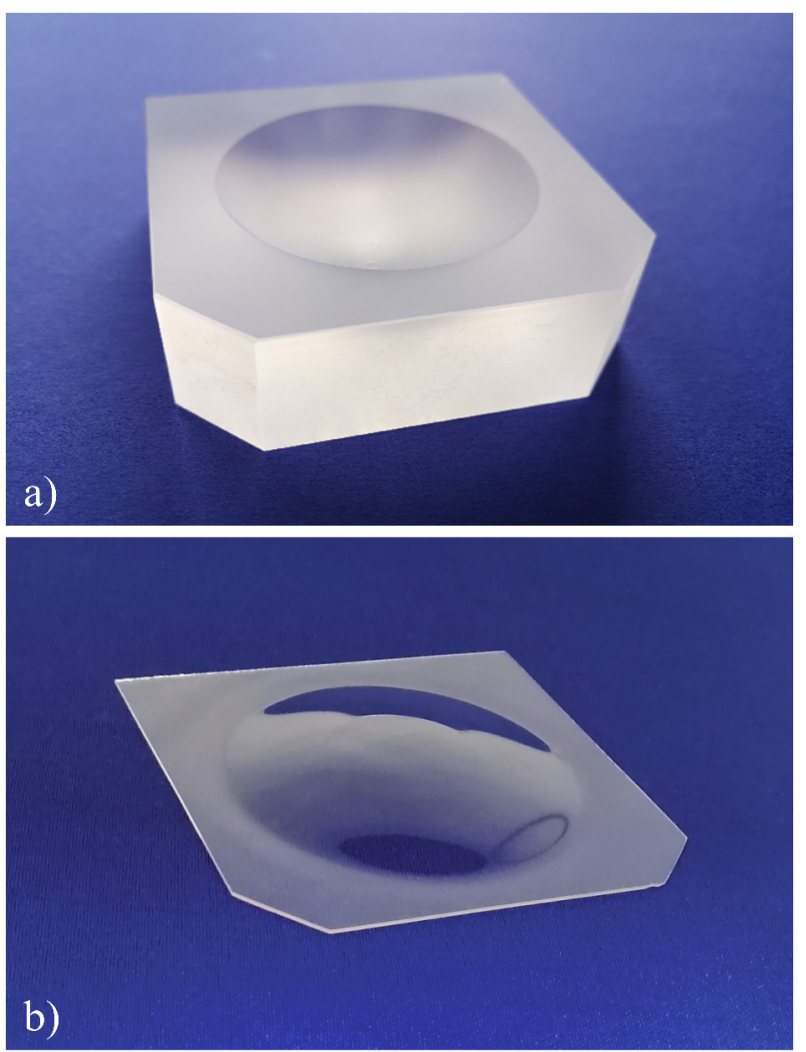

Fig. 4. Gravity-assisted bending of a parabolic mirror. a) forming tool, b) parabolic mirror made of thin glass before the coating process. [4]

The mould can preferably be made of coated steels or nickel-based alloys, ceramics or, as in this case, fused silica. It should have certain surface properties that lead to easy demoulding of the glass without any sticking behaviour. Otherwise, the glass may be damaged and, in the worst case, the mould could be destroyed. The mirror shown, made of BOROFLOAT ${ }^{\circledR} 33$ (SCHOTT AG), can subsequently be edge-machined and coated, depending on the intended application. $[4,5]$

\section{Conclusion and outlook}

The hybrid glass forming process was successfully implemented. With the two-part experimental setup, it is possible to bend thin glasses under the influence of temperature and gravity, followed by partial deepdrawing with the help of $\mathrm{CO}_{2}$ laser radiation and vacuum, and finally create inner and outer contours by laser cutting. As two of the sub-processes are laser-based, the procedure leads to a significant reduction in processing time compared to conventional forming processes. In the future, it is desirable to realise all sub-processes of the hybrid process in one test facility, especially with a view to industrial application. This would be accompanied by further considerable savings in terms of costs, time and energy, as the glass elements only have to be heated once, so that only one annealing process would be necessary.

Another positive aspect is that the process can be well adapted to other glass materials. If the material-specific viscosity fixed points are known, the required process temperatures, even for new types of glass, can be determined by calculation. This expands the potential fields of application of the individually formed glass elements, so that the process can be interesting for many different target groups.

In conclusion, the innovative process combination enables the production of new component designs that are not feasible with current state-of-the-art methods. This is intended to open up new areas of application, for example in the automotive industry as well as in medical technology, entertainment industry (e.g. for smartphones or tablets), building architecture or optics.

The authors gratefully acknowledge the financial support by the German Federal Ministry for Economic Affairs and Energy and the AiF-Projekt GmbH (funding reference: ZF4039612AG8).

\section{References}

1. J. Bliedtner, G. Gräfe, R. Hector: Optical technology. McGraw-Hill Education. (2011)

2. G. Nölle: Technik der Glasherstellung. Freiberg: Wiley-VCH Verlag GmbH \& Co. KGaA. (1997)

3. R. Hassel, A. Barz, J. Bliedtner, J. Steuer, H. Pitcha, M. Eberlein: Neuartige Prozesskette zum hybriden laserstrahlunterstützten Thermoformen von 3DGlaselementen. 12. Jenaer Lasertagung, DVSBerichte Vol. 367, Page 252. (2021)

4. J. Bliedtner: Optiktechnologie: Grundlagen - Verfahren - Anwendungen - Beispiele. 3., überarbeitete und erweiterte Auflage. Carl Hanser Verlag GmbH \& Co. KG. (to be published)

5. D. Rieser: Untersuchungen zum Klebe- und Abriebverhalten von Formenwerkstoffen für die Heißformgebung von anorganischem Glas. Dissertation. Universität Karlsruhe. (2004) 